\title{
Coroas provisórias 3D X coroas analógicas: pesquisa experimental
}

\author{
3D temporary crowns $\mathbf{X}$ analog crowns: experimental research \\ Coronas temporales 3D frente a coronas analógicas: investigación experimental
}

Recebido: 21/10/2021 | Revisado: 31/10/2021 | Aceito: 01/11/2021 | Publicado: 03/11/2021

Luiz Otavio Rovina Arroio

ORCID: https://orcid.org/0000-0003-1608-386X Universidade Brasil, Brasil

E-mail: duduarroio138@gmail.com

Caroline Liberato Marchiolli

ORCID: https://orcid.org/0000-0001-8881-4882 Universidade Brasil, Brasil

E-mail: caaliberato@gmail.com

Maria Eduarda de Freitas Santana Oliveira

ORCID: https://orcid.org/0000-0002-4074-4288 Universidade Brasil, Brasil

E-mail:mariaefreitas10@gmail.com

Jéssica Monique Lopes Moreno

ORCID: https://orcid.org/0000-0002-8808-4872

Universidade Estadual Paulista "Júlio de Mesquita Filho", Brasil

E-mail: jessica_morenoo@hotmail.com

\begin{abstract}
Resumo
As coroas provisórias são parte fundamental aos tratamentos reabilitadores, essenciais para manutenção da integridade marginal do preparo do dente, bem como a proteção do complexo dentino pulpar afim de evitar sensibilidade, caries e problemas gengivais. Atualmente existem diversas técnicas para sua confecção tendo como base os derivados tipos de resina acrílica e as tecnologias mais recentes. Este trabalho teve como objetivo realizar uma pesquisa experimental com 3 tipos de técnicas afim de verificar quais as vantagens e desvantagens das mesmas, tempo de trabalho, quais materiais são necessários para sua utilização, e verificar o conhecimento dos cirurgiões-dentistas quanto as mais atuais tecnologias. Podemos concluir que todas as técnicas apresentam vantagens e desvantagens significativas e que todas são úteis no dia a dia do cirurgião-dentista independente do seu tempo de atuação, apesar da tecnologia mais recente ser ainda inviável em muitos consultórios devido seu alto custo.
\end{abstract}

Palavras-chave: Coroas provisórias; Impressão 3D; CADCAM.

\begin{abstract}
Temporary crowns are a fundamental part of rehabilitative treatments, essential to maintain the marginal integrity of the tooth preparation, as well as to protect the dentine pulp complex in order to avoid sensitivity, caries and gingival problems. Currently, there are several techniques for its manufacture, based on acrylic resin derivatives and the latest technologies. This work aimed to perform an experimental research with 3 types of techniques in order to verify their advantages and disadvantages, working time, which materials are necessary for their use, and to verify the knowledge of dental surgeons about the most current technologies. We can conclude that all techniques have significant advantages and disadvantages, and that all are useful in the daily routine of the dentist, regardless of how long he or she has been working there, although the most recent technology is still unviable in many offices due to its high cost.
\end{abstract}

Keywords: Temporary crowns; 3D impression; CADCAM.

\section{Resumen}

Las coronas provisionales son una parte fundamental de los tratamientos de rehabilitación, esenciales para mantener la integridad marginal de la preparación del diente, así como para proteger el complejo pulpar de la dentina con el fin de evitar sensibilidad, caries y problemas gingivales. En la actualidad, existen varias técnicas para su fabricación basadas en los derivados de la resina acrílica y en las últimas tecnologías. Este trabajo tuvo como objetivo realizar una investigación experimental con 3 tipos de técnicas para verificar sus ventajas y desventajas, el tiempo de trabajo, qué materiales son necesarios para su uso, y verificar el conocimiento de los cirujanos dentales sobre las tecnologías más actuales. Podemos concluir que todas las técnicas tienen importantes ventajas e inconvenientes y que todas son útiles en la rutina diaria del dentista, independientemente de su antigüedad, aunque la última tecnología sigue siendo inviable en muchas consultas debido a su elevado coste.

Palabras clave: Coronas temporales; Impresión en 3D; CADCAM. 


\section{Introdução}

A relevância das restaurações provisórias é indiscutível quando se trata de um tratamento intraoral, possuindo múltiplas finalidades tais como, proteção do dente preparado, manutenção da saúde periodontal e pulpar, restauração estética e funcional, manutenção ou ganho das dimensões verticais de oclusão, estudo diagnóstico e preservação as relações oclusais. O provisório, tem o papel fundamental para que se obtenha um sucesso na restauração definitiva. Os materiais resinas acrílica eram usados para a confecção de uma coroa provisória desde a década 30, obtendo uma boa biocompatibilidade e uma estética desejável e além de trazer um baixo custo. Porém os materiais provisórios ainda necessitam de melhorias por não suportar certas forças mastigatórias, trazendo consequentemente a fratura do elemento. As resinas utilizadas para a confecção atualmente são:

A Resina autopolimerizável (RAAQ): É um processo mais comumente. É uma mistura entre monômero é composto por líquido metil metacrilato e possui um inibidor de polimerização de forma natural, a hidroquinona e o polímero, já com as partículas do monômero acionadas, causando o polimetilmetacrilato, que vem seguido do peróxido de benzoíla que executa a ativação da polimerização.

A Resina termopolimerizável (RAAT): O processo de aquecimento é conhecido como ciclo de polimerização ou cura, as suas moléculas se unem através do calor, o seu ativador é o peroxído de benzoíla. Porém ainda nos dias atuais, a técnica é vista como uma forma mais difícil, pois leva um tempo maior para ser confeccionado.

Os materiais utilizados para a confecção das peças provisórias, são especificas, sendo principalmente as resinas acrílicas que possuem características de compatibilidade biológica, facilidade de manipulação, estética adequada, estabilidade química. A resina bisacrilica que veio após, tem ganhado bastante destaque por ser um produto com características positivas, que viabilizam sua utilização nas restaurações provisórias. Dentre as principais, destacam-se: menor percentual de contração de polimerização, maior resistência a flexão e melhor adaptação marginal. Estes pontos positivos são destaques, especialmente quando comparadas a resina bisacrilica à resina acrílica quimicamente ativada. A literatura nos mostra que a facilidade manipulação e aplicação se torna mais viável frente ao material quimicamente ativado. Comparando com a resina fotoativada, a resina bisacrilica ainda apresenta vantagens como o ganho de tempo clinico. De acordo com o Camacho, et all (2014, p.52), as resinas acrílicas: são classificadas como Polímeros e após a fusão, apresenta-se uma característica rígidas e borrachoides. E a suas qualidades são, biocompatibilidade, estabilidade dimensional e tem uma aparência desejável. Com o passar dos anos, as técnicas se tornaram mais fáceis de serem executadas e tendo suas propriedades melhoradas. Nos métodos mais atuais, como a impressora 3D que utilizam resinas, os principais métodos SLA (esterolitografia), DLP (processamento digital de luz) e LCD (display de cristal líquido). Todas essas tecnologias partem do mesmo princípio: a cura da resina para formar a peça, e o que as difere é a fonte de luz que será utilizada no processo. O processo de impressão 3D ocorre em um grande tanque cheio de resina líquida, então a fonte de luz é aplicada (dependendo a tecnologia utilizada), partes seletivas do liquido são endurecidas, dependendo do local onde a fonte de luz entra em contato. O material restante no tanque permanece líquido. A escolha da melhor resina dependerá das necessidades da peça que será impressa e do tipo de impressora que vai ser utilizada. Certificar qual o comprimento de onde e se é compatível com a impressora 3D. Deve-se levar em conta para a escolha da resina: qualidade de acabamento, resistência mecânica, transparência, biocompatibilidade. As coroas provisórias podem ser feitas de formas diretas ou indiretas, podendo ser realizadas direto na boca pelo cirurgião-dentista. Ou indireta onde é necessário a moldagem ou escaneamento intra oral para envio do laboratório. Geralmente quando os provisórios vão ser usados por um longo prazo ou como ferramentas de diagnóstico, os fabricados em laboratório são melhores porque seus materiais fornecem maior resistência ao desgaste e descoloração, além de dar uma ideia mais precisa do que vai ser a reabilitação final ao paciente. O planejamento é realizado junto ao paciente para que ele possa aprovar, formas, contornos, aparência, sempre checando oclusão. Após aprovação do tratamento, dentes seguem para ser preparados para reabilitação final. A adesão geralmente das coroas provisórias é utilizada cimentos temporários, para que não haja problemas maiores em sua retirada. 
O objetivo do presente trabalho é apresentar a expansão de aproveitamento de impressões 3D em trabalhos odontológicos, demonstrando um método de provisório dentário usando a impressão 3D, pela técnica SLA, comparando com as outras técnicas analógicas, suas vantagens ou desvantagens e trazendo um conceito de modernização aos consultórios odontológicos.

\section{Metodologia}

Foram realizadas duas pesquisas, uma quantitativa e uma in vitro com a finalidade de avaliar o conhecimento sobre a impressão 3D com os profissionais, e analisar aspectos dos dentes das técnicas utilizadas, para isso, 10 cirurgiões dentista da cidade de Fernandópolis/SP contribuíram com a pesquisa.

\subsection{Pesquisa quantitativa.}

A pesquisa compõe 8 perguntas, sendo eles; Nome, sexo, tempo de experiencia, quais são as formas que utilizam para confeccionar o provisório dentário, se sabem do potencial que a impressora 3D consegue alcançar na área odontológica, se tem o conhecimento do provisório dentário impressos em 3D, e o que impede de investir em uma impressora 3D. Através do modelos prontos, foram feitas 3 perguntas para os mesmos verificarem qual é a anatomia bem mais apresentada entre os três métodos, qual possui melhor adaptação marginal e qual possui melhor polimento entre os provisórios.

\subsection{Pesquisa in vitro.}

Foi realizado corpos de prova com o objetivo de comparar as técnicas, confeccionando 4 dentes de cada técnica sendo eles, incisivos superiores centrais e laterais, 11,12,21 e 22 .

\section{Resultados e Discussão}

Os processos utilizados para construção do provisório são as técnicas das facetas e impressões negativas, ambas são analógicas e pode ser feito direto na boca do paciente ou indiretamente, ou seja, as coroas provisórias são confeccionadas pelo técnico em prótese dentária. Ainda há dificuldades quando se realiza as técnicas analógicas, por ser uma confecção de dentes que precisam reproduzir cor, formato, textura aos seus dentes adjacentes. A técnica da faceta, é aplicado a um dente de estoque, este elemento é composto por resina acrílica, a seleção do dente compatível deve obedecer aos seguintes parâmetros como, altura, largura, cor e formato. Após a escolha, deve-se remover com maxcut a face palatina e isolando com vaselina sólida o preparo dental e nos dentes adjacentes, em seguida com a resina preparada, aguardar o estado plástico, posicionar faceta na posição correta e acrescentando a resina na face palatina e modelando-a. Aguardar a polimerização em boca, em seguida é preciso desgastar o interior do provisório para executar um reembasamento pela técnica de NEALON, removendo excessos e verificando adaptação correta no terço cervical, para posteriormente ser efetuado o perfil de emergência adequado, os itens empregados de acabamento são brocas, discos e lixas, o polimento é efetuado com kits de borrachas e pasta polidora, obtendo uma superfície lisa são menores as probabilidades de acumulo de biofilme dental. Os dentes de estoque são selecionados seguindo a cor, tamanho e forma dos dentes naturais e, posteriormente, desgastados em sua face lingual, cervical e/ou incisal, até serem completamente adaptados sobre os dentes preparados no modelo de gesso. As facetas são unidas entre si com resina para serem posteriormente reembasadas na boca. (PEGORARO, 2013, p.179). Já a técnica de impressão negativa, ocorre a preparação da resina acrílica, chegando em seu estado plástico, efetua-se um cilindro posicionando sobre o dente, conferindo a adaptação nas faces axiais, em seguida com a resina em boca, solicita-se para que o paciente oclua em máxima intercuspidação habitual (MIH) para registrar oclusão dos dentes antagonistas ${ }^{13}$. As vantagens das resinas são, material de baixo custo, facilidade de manuseio, boa adaptação marginal, possibilidade de ajustes, reembasamentos necessários e fácil polimerização. E desvantagens são, por ser um dente 
provisório, a sua duração é curta, porosidades na coroa e limitação de cor ${ }^{1}$. Segundo Mezzomo (2004, p.60), “A confecção da técnica é acomodar um bloco de resina acrílica sobre o dente, procurando adapta-lo principalmente aos espaços proximais e em todo o perímetro cervical e orientar o paciente para que oclua em MIH." A técnica direta, hoje em dia, se tornou mais popular, pois essa técnica permite realizar em sessão única no próprio consultório de forma simples e breve. Segundo o autor Silva José, (2011, p-60), a técnica indireta, os cirurgiões dentistas não participam nas confecções dos provisórios, eles apenas realizam a moldagem prévia e a cimentação dos elementos. A execução das coroas temporárias é realizada em laboratórios. Com o auxílio de softwares e maquinário compatível a Era da odontologia digital, vem cada vez mais facilitando esses procedimentos odontológicos e protéticos, trazendo precisão, redução de tempo em atendimentos e conforto para os pacientes. Desde 1980, a impressão dentária 3D foi sendo discutido, entretanto, ainda há muitas dúvidas e limitações a ser discutidos. O scanner intraoral permite digitalizar arcada dentária de um paciente sem necessidade de moldagem, gerando um modelo tridimensional. E com o sistema CAD (Computer Aided Design), são possíveis de alimentar dados obtidos através do escaneamento e conseguem modificar a forma sem a necessidade de uma cópia física. A impressora 3D, consegue imprimir o protótipo criado através do Software, e ele permite realizar um planejamento dentário, produzir próteses com a maior precisão. A impressora em resinas, possuem duas técnicas, SLA (tecnologia de estereolitografia a laser) e DLP (processamento digital de luz). "A Impressão em 3D, ou fabricação aditiva, consiste na criação de um objeto físico por impressão, camada sobre camada, de um modelo ou desejo digital em 3D". (Schwab,2016, P. 152). A tecnologia SLA, teve a sua origem em 1980, por Charles Hull, segundo ele, é um método de elaborar um objeto 3D por camadas através de impressão A impressora possui uma cuba, onde fica arquivado a resina líquida, e com a alta potência do laser Ultravioleta (UV), causa à polimerização do material e constroem um trabalho de cima para baixo. Já a técnica DLP, usa-se um projetor de luz digital que expõe uma única imagem por camada em toda a plataforma de uma vez só. A resina é um polímero fotossensível adquiridos na forma líquida e pode ser variada de acordo com a propriedade de impressora e do tipo de protótipo, dessa forma, pode mudar a cor, a sua resistência, e a elasticidade.

Tabela 1 - Comparação das técnicas, matérias, tempo gasto individualmente apresentada por cada técnica.

\begin{tabular}{|c|c|c|c|c|}
\hline TECNICAS UTIIZADAS & MATERIAL & EOUIPAMENTO & POLIMENTO & TEMPO DE CONFECCCุÃO \\
\hline \multirow{5}{*}{ ANALÓGICAS } & \multirow{3}{*}{ VASELINA EM SOLIDA } & ESPATULA N0 24 & \multirow{3}{*}{ KIT POLIDOR (JOTA) } & \multirow{5}{*}{2 HORAS } \\
\hline & & DAPPEN & & \\
\hline & & MOTOR CONTRA ÁNGULO & & \\
\hline & \multirow[t]{2}{*}{ RESINA AUTOPOLIMERIZÁVEL. } & BROCA MAX-CUT & \multirow{2}{*}{ PASTA POUDORA DIAMOND (FGM) } & \\
\hline & & LAP15 & & \\
\hline \multirow{6}{*}{ ANALÓOGICAS } & \multirow{2}{*}{ VASELINA SOUDA. } & ESPATULA NE 24 & \multirow{4}{*}{ KIT POLIDOR (JOTA) } & \multirow{6}{*}{1 HORA E 3OMINUTOS } \\
\hline & & DAPPEN & & \\
\hline & & MOTOR CONTRA ÃNGULO & & \\
\hline & RESINA AUTOPOLIMERIZAVEL & BROCAMAX-CUT & & \\
\hline & \multirow{2}{*}{ DENTE DE ESTOQUE (NEW ACE) } & LÁPIS & \multirow[t]{2}{*}{ PASTA POUDORA DIAMOND ( FGM) } & \\
\hline & & BROCA CARBITE NN 10 & & \\
\hline \multirow{7}{*}{30} & \multirow{2}{*}{ RESINA LIQUIDA (YLLER COSMOS) } & SCANNER INTRAORAL (STRAUMANN VIRTUO VIVO) & \multirow{4}{*}{ IMPRESSÃO JÁ COM O BRILHO } & \multirow{7}{*}{3 HORAS } \\
\hline & & COMPUTADOR & & \\
\hline & \multirow{2}{*}{ ÁLCOOL BSOPROPILICO } & SOFTWARE EXO CAD & & \\
\hline & & IMPRESSORA 30 PHOTON S [ANYCUBIC\} & & \\
\hline & \multirow{2}{*}{ CIMENTO HYORO C (DENTIPLY SIRONA) } & CUBA ULTRASSONICA (CRISTÓFOLI) & \multirow{3}{*}{ PASTA POLIDORA DIAMOND ( FGM ) } & \\
\hline & & CABINE DE CAMARÅ DE LUZ UV (EDG) & & \\
\hline & HO RETRATOR OOO (ULTRAPAC) & PEN DAIVE & & \\
\hline
\end{tabular}

Fonte: Autores.

Inicialmente realizamos a pesquisa in vitro onde foram feitos 4 dentes através da técnica impressão negativa, começamos preparando os moldes de dente, após isso, isola-se com a vaselina sólida os dentes adjacentes e antagonista. prepara resina autopolimelizavel em um dappen de vidro utilizando a espátula nº24, e manipula-se o monômero e polímero até ficar homogenias, e assim que a resina perder o seu brilho e transformar no estado de plástico, remove do recipiente e começamos a fazer um cilindro, e aplicando sobre os preparos dentais e copiando as faces Inter proximais, e retirando o dente para realizar as 
demarcações no provisório com um lápis e removendo o excesso e deixando o espaço no alívio interno. Feito isso, preparamos a resina novamente para realizar o reembasamento, e após atingir a sua fase, fazemos novamente o cilindro, preenchemos a resina no alívio interno e copiando novamente sobre o preparo e pressionando o excesso que ficar para determinar a altura oclusal (DVO) e o acabamento é feito com a broca max cut e por último o polimento, utilizamos as borrachas (kit polidor), para deixar superfície lisa e a pasta polidora para dar o brilho. O tempo gasto para realizar os 4 dentes, foram de 2 horas.

Figura 1 - Modelo com preparos.

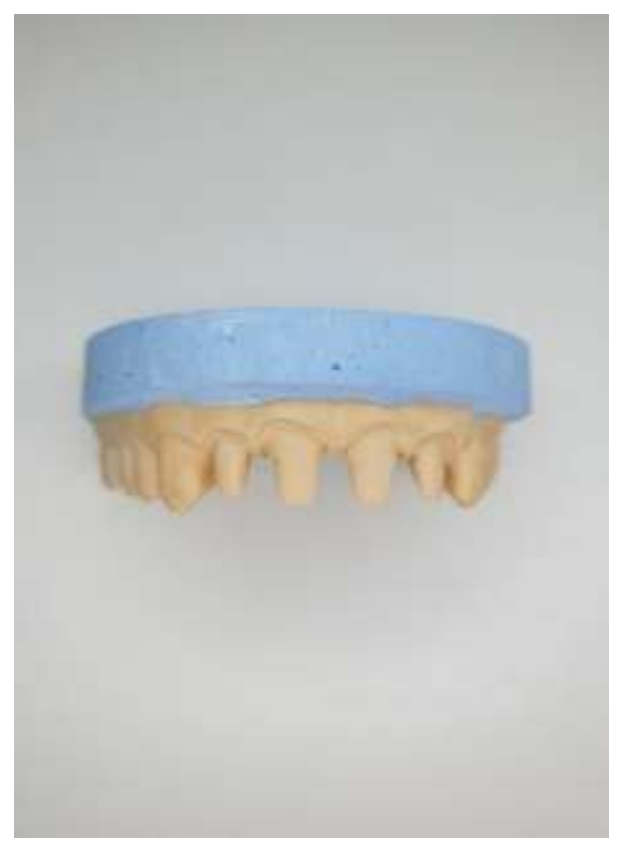

Fonte: Autores.

Figura 3-Reembasamento cervical.

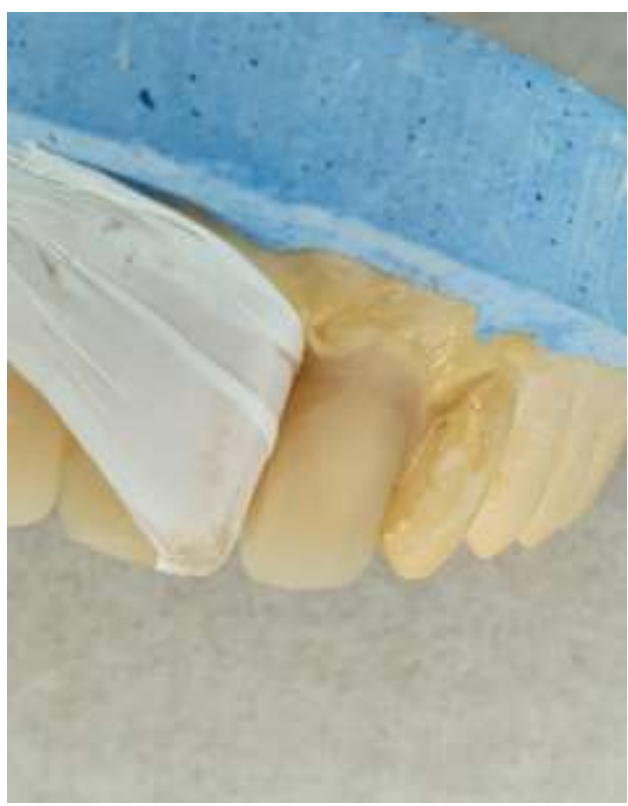

Fonte: Autores.
Figura 2 - Preparação da resina em cilindro.

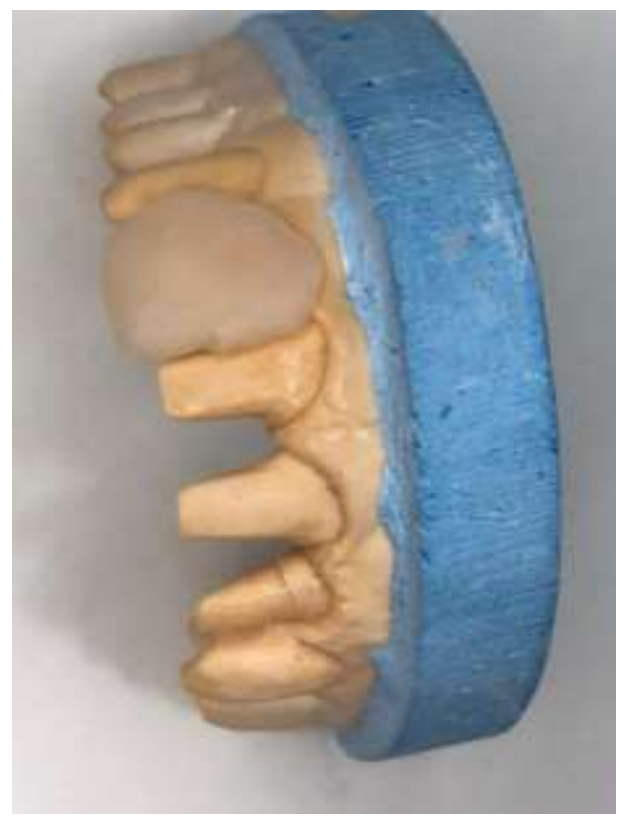

Fonte: Autores.

Figura 4 - Delimitação cervical e remoção excessos.

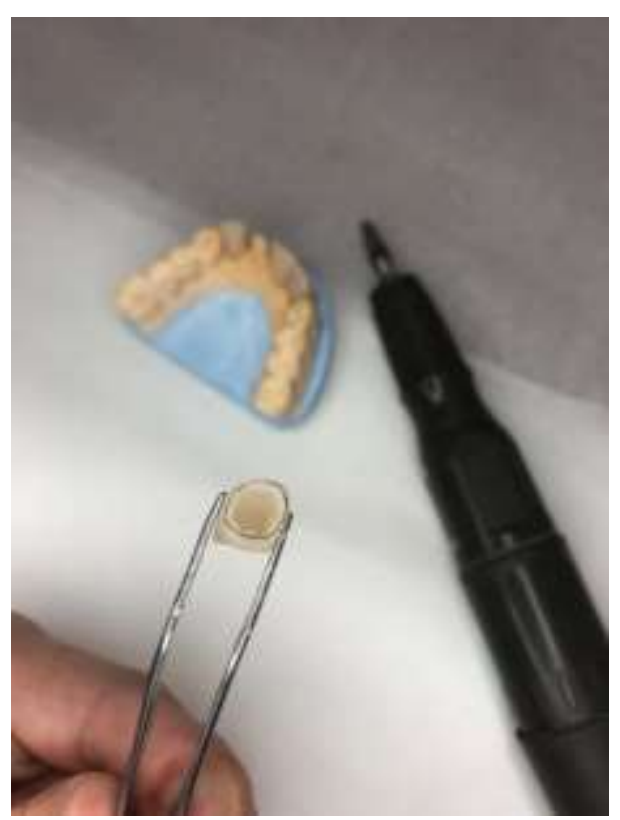

Fonte: Autores. 
Figura 5 - Provisórios prontos via frontal.

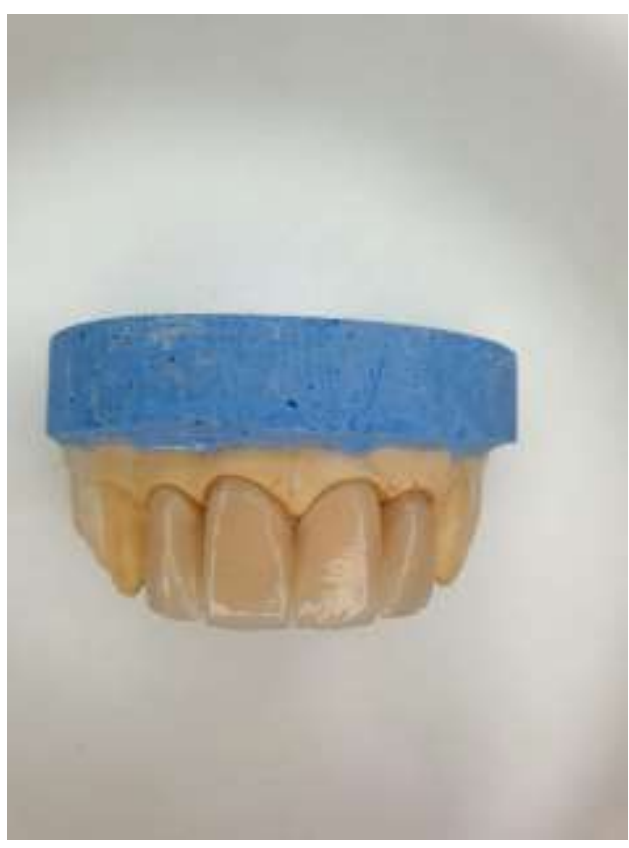

Fonte: Autores.
Figura 6 - Provisórios prontos via oclusal.

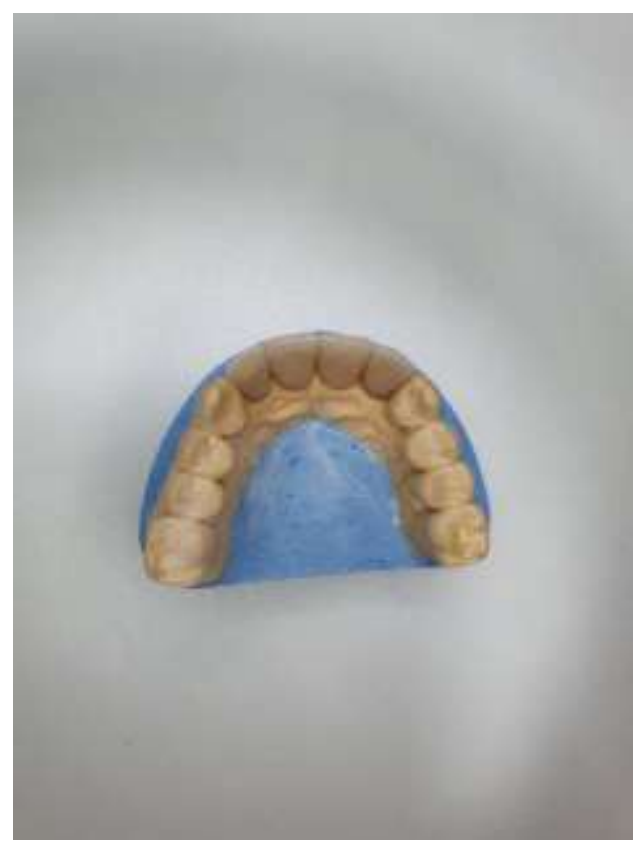

Fonte: Autores.

Em seguida, utilizamos a técnica das facetas para fabricar os dentes, o processo é semelhante ao da impressão negativa, inicia-se com a escolha dos dentes do estoque conforme as referências dos dentes do paciente, altura, formato e cor. Após a escolha, desgastamos a face palatina e Inter proximais com o max cut para que encaixe no terço cervical e no perfil de emergência. Logo isso, aplica-se a vaselina nos dentes e preparamos a resina, o material e o equipamento são iguais ao da impressão negativa. Assim que a resina chegar no estado de plástico, acrescentamos o material na fase palatina do dente de estoque e levar o conjunto em boca do preparo. Seguidamente retiramos o excesso e efetuar o alívio interno da coroa com a broca $\mathrm{n}^{\circ} 10$ para que possamos fazer o reembasamento. A partir desse modo, o reembasamento, acabamento e polimento é igual a outra técnica citada no texto acima. O processo de confecção durou 1 hora e 30 minutos.

Figura 7 - Modelo com preparos.

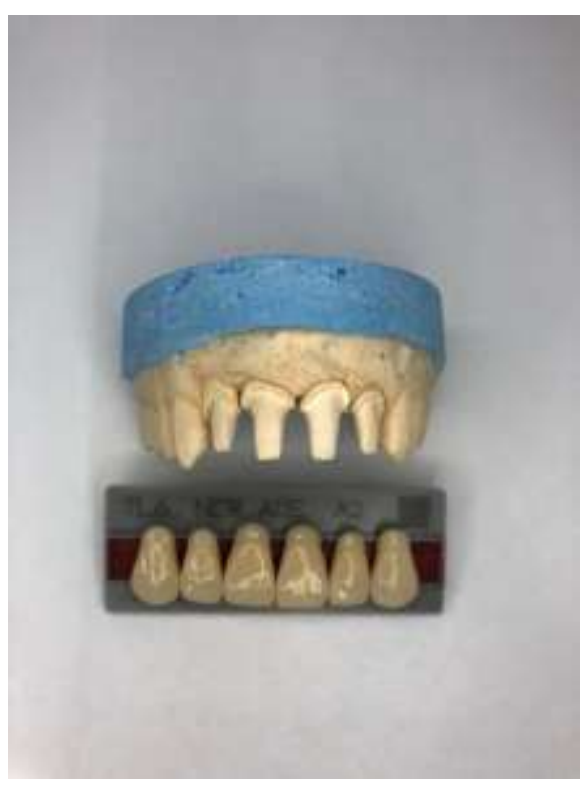

Fonte: Autores.
Figura 8 - Posicionamento dos dentes na arcada.

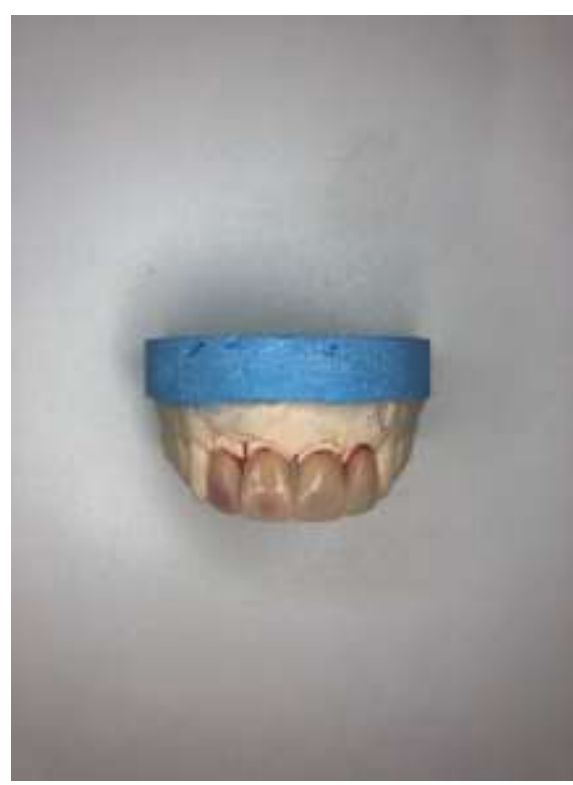

Fonte: Autores. 
Figura 9 - Reembasamento cervical com resina

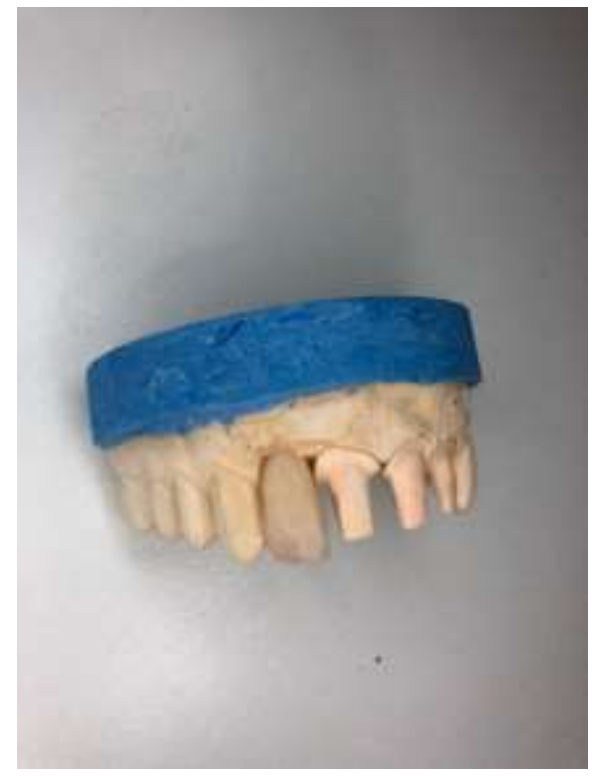

Fonte: Autores.

Figura 11 - Provisórios instalados visão frontal.

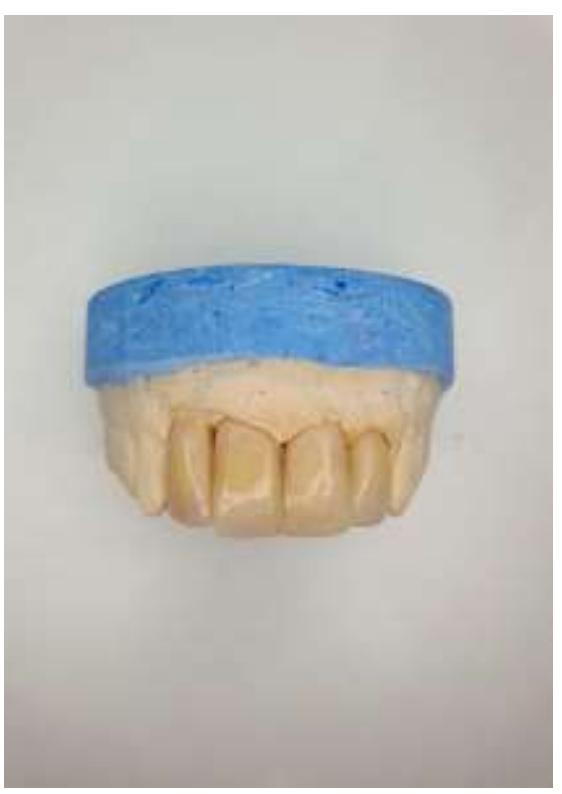

Fonte: Autores.
Figura 10 - Adaptação marginal após reembasamento autopolimerizavel.

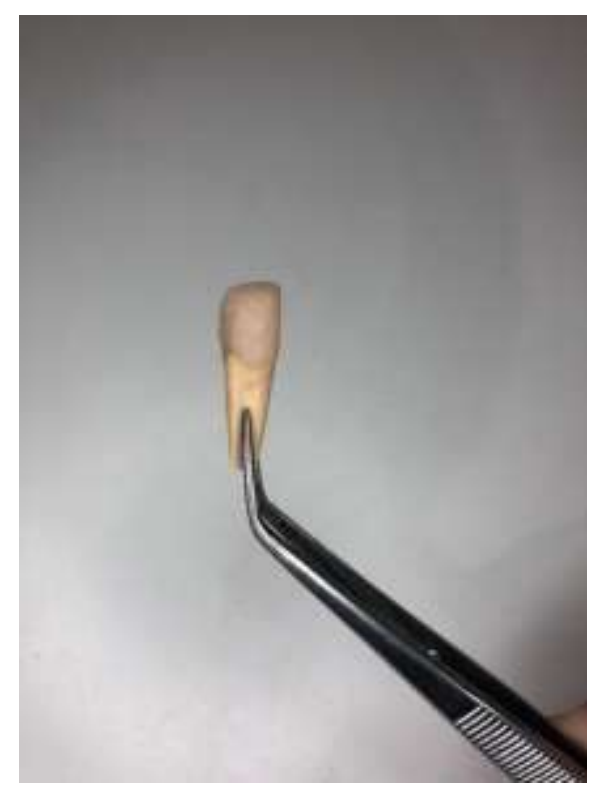

Fonte: Autores.

Figura 12 - Provisórios instalados visão oclusão.

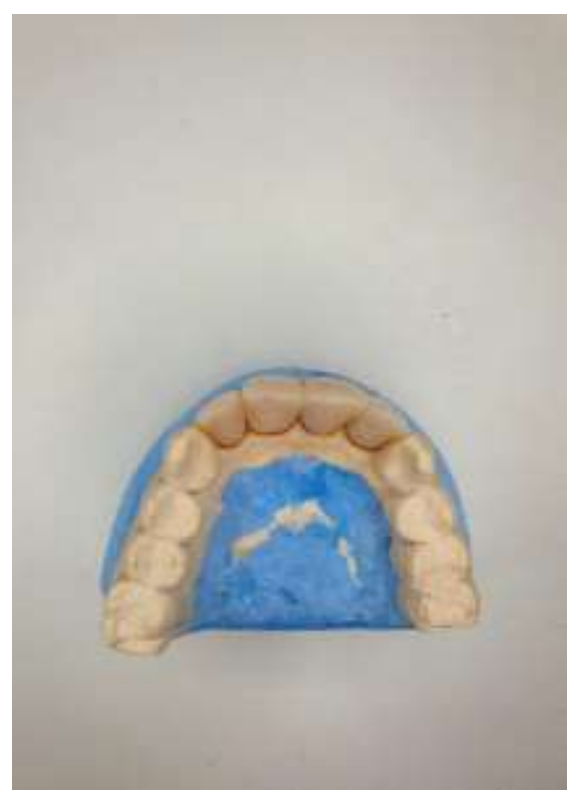

Fonte: Autores.

E por último, com a técnica SLA feito com a impressora 3D, o cirurgião dentista começa preparando os dentes e faz o afastamento gengival com fio retrator 000. E logo em seguida, inicia o escaneamento digital da arcada superior onde iremos confeccionar os provisórios. Após o escaneamento, o software irar gerar arquivos em STL das arcadas selecionados. No programa, será selecionado os dentes que serão impressos, e iremos delimitar a margem cervical, definir o eixo de inserção. Obtendo assim a praticidade na hora da cimentação das coroas. Logo isso, iremos selecionar os dentes em uma biblioteca virtual, onde consta as referências dos dentes superiores, e fazemos o posicionamento adequado dos elementos arcada e vista frontal. E adaptamos os mesmos nos preparos e removemos o excesso nas faces proximais e oclusais dentro do software. Com as coroas prontas, enviamos o arquivo no pen drive e conecta-se na entrada usb da impressora 3D. E assim começa a impressão dos dentes, usando a resina líquida A1. O tempo de impressão é de 1 hora e 30minutos. Depois de impressos, mergulhamos os protótipos no álcool isopropílico em 3 a 5 minutos dentro de uma cuba ultrassônica, ele emite as ondas sonoras e isso permite retirar os excessos 
da retina líquida que fica inferior da coroa. E por último coloca as coroas em uma câmara de luz UV, para que possa finalizar a pós cura e polimerização. O tempo de pós cura é de 10minutos. O tempo de confecção ao todo é de 3 horas.

Figura 13 - Definição do trabalho para ser realizado.

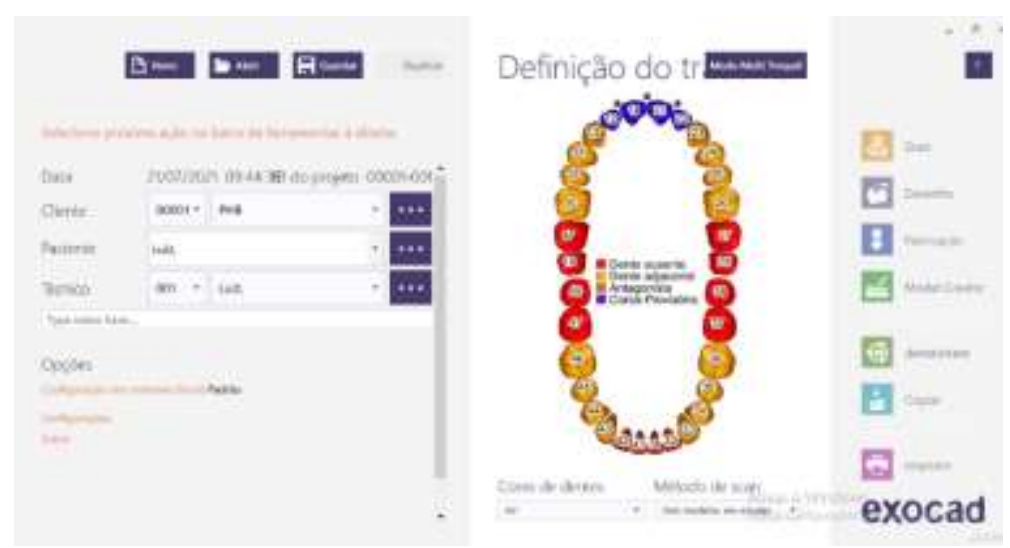

Fonte: Autores.

Figura 14 - Preparos para confecção de futuras próteses

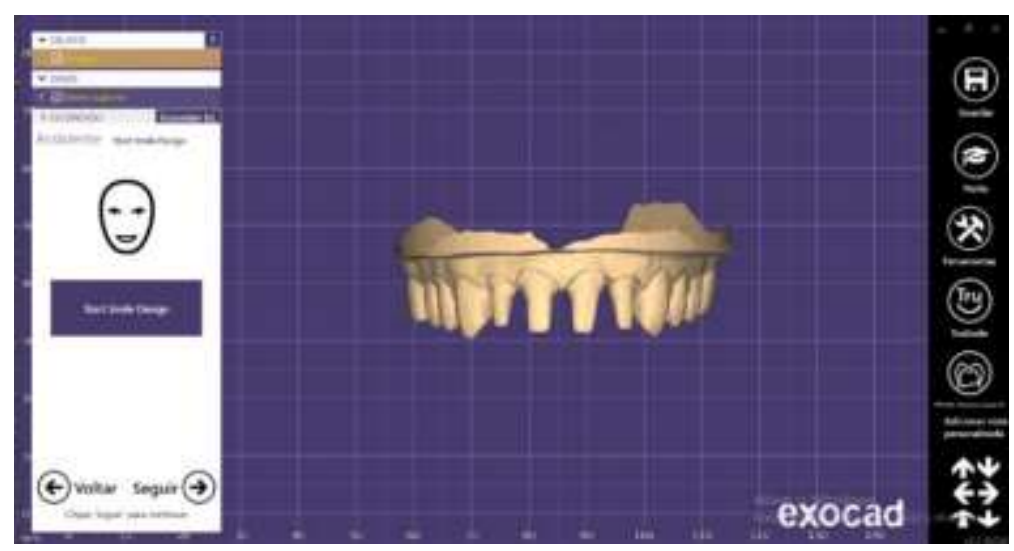

Fonte: Autores.

Figura 15 - Delimitação da região cervical de cada preparo.

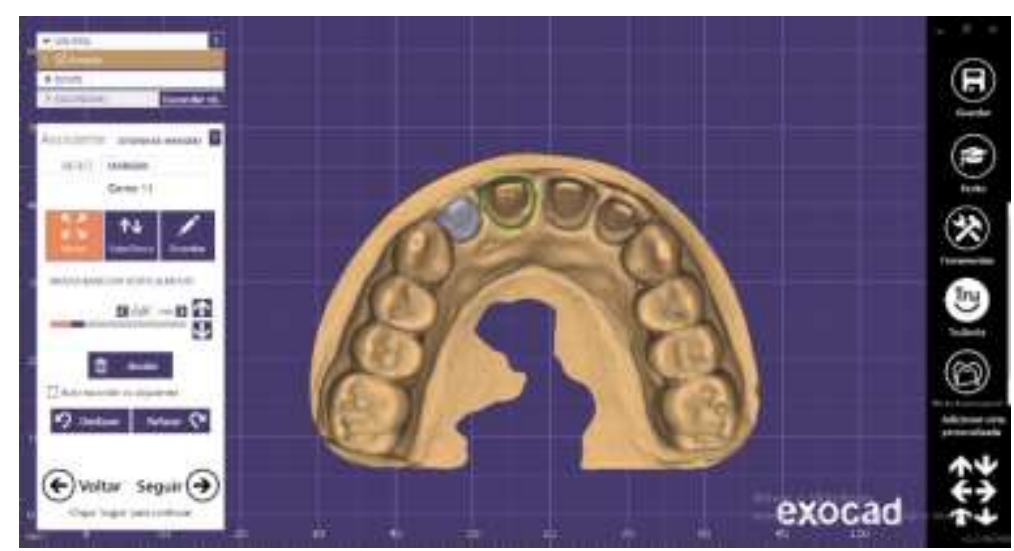

Fonte: Autores. 
Figura 16 - Anatomia escolhida e ajustes proximais.

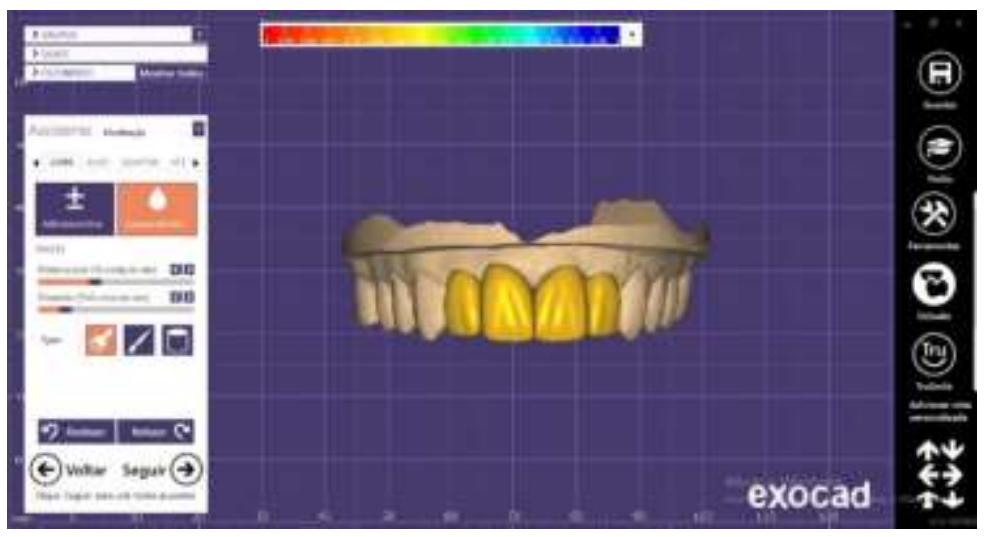

Fonte: Autores.

Figura 17 - Coroas finalizadas dentro do CAD, prontas para impressão.

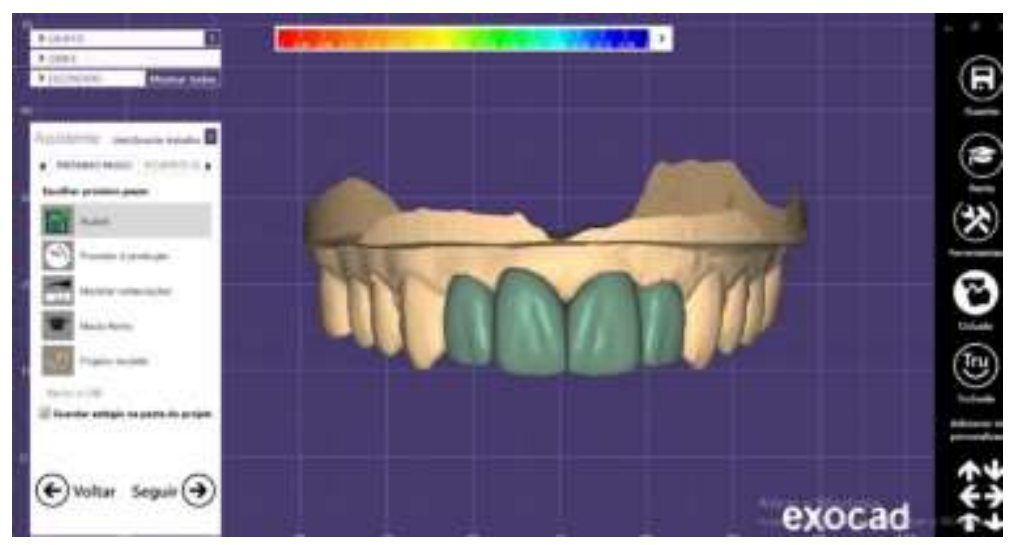

Fonte: Autores.

Posteriormente seguimos entrevistando os 10 cirurgiões-dentistas selecionados para a pesquisa quantitativa onde todos foram questionados sobre as 3 técnicas usadas, quais mais utilizam dentro do consultório hoje em dia, qual o conhecimento e experiencia com a tecnologia e vantagens da impressora 3D. Primeiro profissional entrevistado foi o Dr. Adriano, atua há 23 anos. O primeiro questionamento foi, “Qual é a forma que você utiliza para fazer o provisório dentário?”. De acordo com sua resposta, ele usa a técnica da faceta. A segunda pergunta realizada foi, "Se possui o conhecimento de que a impressora 3D pode atuar na área odontológico, e se a resposta for sim, investiria?" Onde obteve-se a resposta de que possui o conhecimento, porém não investiria agora devido alto custo dos equipamentos necessários. Segundo profissional entrevistado foi a Dra. Amanda, atua há 2 anos. Primeira pergunta foi, "Qual é a forma que você utiliza ao fazer a coroa provisória?". Ela respondeu que utilizada a técnica da faceta. A seguir, foi perguntado se possui conhecimento de que a impressora 3D, atua na área odontológica, e se a resposta sim, se investiria? Onde respondeu que sim, porém ainda tem dúvidas e não possui conhecimento ao ponto de investir. Terceiro profissional entrevistado foi o Dr. João Gabriel, atua há 03 anos. Primeira pergunta foi, "Qual método de provisório que você faz em seus atendimentos?". Ele respondeu que emprega a técnica da faceta. A seguir foi perguntado se possui o conhecimento de que a impressora 3D, atua na área odontológica, e se investiria numa impressora 3d. E ele disse que sim, mas para ele é inviável no momento, pois é um alto investimento. Quarto profissional entrevistado a ser entrevistado foi o Dr. João Ricardo, atua há 03 anos. Fizemos as mesmas perguntas para ele. E ele respondeu que utiliza a técnica faceta. E possui o conhecimento sobre a impressora 3D na área odontológica, porém não investiria devido a alto custo. Quinto profissional entrevistado foi a Dra. Mayara, atua há 10 anos. Foi interrogada a ela, "Qual é a forma utilizado para confeccionar os dentes provisórios?", e de acordo com a sua resposta foi faceta. A segunda pergunta realizada foi se ela possui conhecimento sobre a 
impressora 3D na área odontológica, e se sim, investiria? De acordo com a sua resposta, ela tem o conhecimento, porém devido a alto investimento, não tem interesse. Sexto profissional entrevistado foi o Dr. Robson, atua há 03 anos. De acordo com ele, utiliza-se a técnica da faceta no dia a dia. Ele possui conhecimento sobre a área 3D, porém ele relata alto investimento e não tem interesse no momento. Sétimo profissional entrevistado foi o Dr. Renato Cesar, atua há 02 anos. Ele relata que utiliza para sua confecção a técnica da faceta, próxima pergunta foi se ele tem conhecimento sobre a impressora 3D no ramo odontológico, ele comentou que sim, porém por estarmos no interior, a tecnologia 3D, ainda fica inviável devido alto custo e falta de conhecimento. Oitavo profissional entrevistado foi o Dr. Paulo, atuando há 28 anos em atendimento odontológico, ele argumentou que utiliza a técnica da impressão negativa, relatou que tem conhecimento das impressões 3D na área odontológica, e também foi perguntado se investiria na tecnologia 3D, e ele respondeu que devido à falta de conhecimento, não pensa colocar em pratica. Nono profissional entrevistado foi o Dr. Fabio, atua há 15 anos em atendimento odontológico, primeira pergunta foi, "qual técnica ele utiliza para produzir um provisório dentário?", onde obteve a resposta que utiliza a técnica da faceta. A pergunta seguinte foi, se tem o conhecimento sobre a tecnologia 3D na área odontológica e o que te impede de investir em uma impressora 3D, a resposta de que sim, tem o conhecimento, porém o mesmo relata alto custo de investimento. Décimo profissional entrevistado foi o Dr. Paulo Henrique, atua há 24 anos. O profissional foi questionado “qual é o método utilizado para confecção dos dentes?", onde a resposta foi a técnica faceta. A próxima pergunta foi relacionado a impressão 3D, se ele possui conhecimento e o que impede de investir nessa área. A resposta foi que sim, tem o conhecimento e ele já investi na tecnologia. Foram confeccionados três modelos gesso, cada modelo com uma técnica provisória diferente, e foi formulado três perguntas sem revelar a técnica de cada modelo, sendo eles. Modelo A técnica da faceta (dente de estoque), Modelo B técnica da impressão negativa e Modelo C Impressão 3D e apresentados para todos os entrevistados.

Tabela 2 - Respostas dos profissionais entrevistados aos modelos apresentados para comparação, sem revelar quais técnicas foram utilizadas.

\begin{tabular}{|c|c|c|c|}
\hline NOME & $\begin{array}{l}\text { QUAL ANATOMIA } \\
\text { BEM MAIS } \\
\text { APRESENTADA } \\
\text { ENTRE AS TRÊS } \\
\text { TECNICAS. }\end{array}$ & $\begin{array}{l}\text { QUAL POSSUI } \\
\text { MELHOR } \\
\text { ADAPTAÇÃO } \\
\text { MARGINAL }\end{array}$ & $\begin{array}{l}\text { QUAL POSSUI } \\
\text { MELHOR } \\
\text { POLIMENTO } \\
\text { ENTRE OS TRÊS } \\
\text { MÉTODOS }\end{array}$ \\
\hline ADRIANO & MODELO A & MODELO C & MODELO A \\
\hline AMANDA & MODELO A & MODELO C & MODELO B \\
\hline JOÃO GABRIEL & MODELO B & MODELO C & MODELO A \\
\hline JOÃO RICARDO & MODELO A & MODELO B & MODELO B \\
\hline MAYARA & MODELO B & MODELO C & MODELO C \\
\hline ROBSON & MODELO B & MODELO C & MODELO A \\
\hline RENATO CESAR & MODELO B & MODELO A & MODELO C \\
\hline PAULO & MODELO B & MODELO C & MODELO C \\
\hline FÁBIO & MODELO C & MODELO B & MODELO B \\
\hline PAULO HENRIQUE & MODELO C & MODELO C & MODELO C \\
\hline
\end{tabular}


Research, Society and Development, v. 10, n. 14, e322101422117, 2021

(CC BY 4.0) | ISSN 2525-3409 | DOI: http://dx.doi.org/10.33448/rsd-v10i14.22117

Tabela 3 - Respostas dos profissionais representado em gráfico.

Qual anatomia bem mais apresentada entre as 3 tecnicas

10 respostas

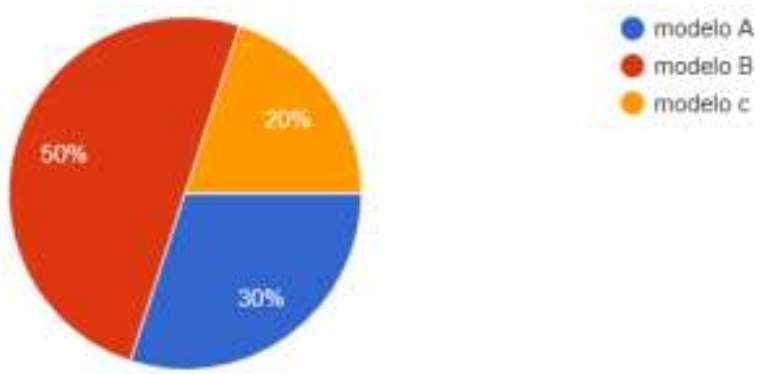

Qual possui melhor adaptação marginal

10 respostas

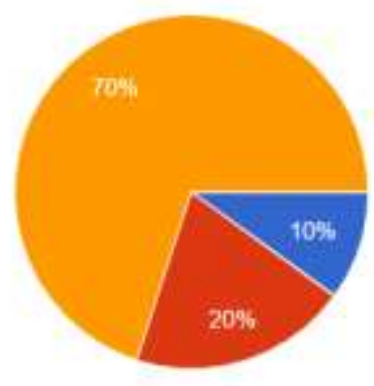

\section{Qual possui melhor polimento entre os trés mètodos}

10 respostas

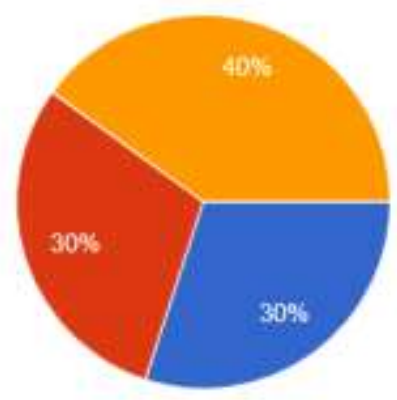

Fonte: Autores.

Abdullah e seus membros (2016) argumentaram que as coroas provisórias produzidos em CAD/CAM demostram adaptação marginal e ajuste interno elevado, além de uma maior força mecânica, colacionando às coroas provisórias diretas. (Abdullah et al., 2016). Segundo Marco Cicciù e os demais autores, a moldagem através da técnica digital, obtém mais qualidades em comparação a técnica analógica, melhorando como a qualidade de reabilitação provisória, economia na atuação odontológica. Segundo Apolinario e seus colaboradores, concluiu que a resina acrílica autopolimerizável é a mais aplicada em provisórios, 
possui baixo custo, fácil manejo, facilidades em consertos e ajustes. E apresenta uma estética agradável e biocompatível aos tecidos gengivais e dentários. Segundo Pegoraro (2014) O mesmo cita algumas vantagens: material é de fácil manipulação, maioria das vezes é confeccionado direto em boca, a coroa é reembasada para melhor adaptação cervical, o custo do material é baixo, necessita maioria das vezes de conhecimento e destreza manual, apresenta media resistência por ser um material temporário e obtendo várias cores para sua confecção.

\section{Considerações Finais}

Podemos concluir que todas as técnicas são eficazes e atendem ao desejo final que é deixar o complexo dentino pulpar protegido para a coroa definitiva e o paciente com dente até receber a reabilitação final. Hoje em dia ainda é inviável financeiramente a tecnologia 3D para muitos consultórios odontológicos, e também faltam aqueles que saibam manejar e manipular tais equipamentos. Pudemos perceber também que para reabilitações menores as técnicas analógicas são mais eficazes pois demoram menos tempo na execução, quanto a tecnologia 3D se sobressai quando as reabilitações são maiores, e independe do tempo de atuação do profissional cirurgião-dentista.

\section{Referências}

Abdullah, A. O., Tsitrou, E. A., \& Pollington, S. (2016). Comparative in vitro evaluation of CAD/CAM vs conventional provisional crowns. Journal of applied oral science, 24(3), 258-263.

Alnassar, T. et al. Shear bond strength of bis-acryl resin provisional material repaired using a flowable composite. Journal of adhesion science and Technology, $32(6), 573-579$.

Baião, F. J. Funcionalidades e Tecnologias da impressora 3D. Monografia apresentada ao curso de Engenharia de Computação da Universidade São Francisco, Itatiba, 2012.

Burns, D. R., Beck, D. A., Nelson, S. K., \& Nelson, S. K. A review of selected dental literature on contemporary provisional fixed prosthodontic treatment: Report of the Committee on Research n Fixed Prosthodontics of the Academy of Fixed Prosthodontics. J Prosthet Dent 2003;90(5):474-497

Camacho, D. P. Svidzinki, T. I. E. Furlaneto, M. B. L. \& Correa, G. O. Resina Acrílicas de Uso Odontológico à Base de Polimetilmetacrilato. - Brazilian Journal of Surgery and Crinical Reserach, 6(3), 63-72.

Cauduro, A. L. Alves, A.P. R. Neves, A. C. C. Patrocinio, M. C. \& Rode, S. M. Analise da rugosidade superficial de uma resina composta fotopolimerizavel e uma resina acrílica termopolimerizavel para facetas protéticas. Rev biociênc. 9(4), 25-30.

Coimbra, J., Almeida, B., \& Viana, H. (2017). Coroas Provisórias No Tratamento Restaurador:. Revista De Odontologia Contemporânea, 1(1). https://doi.org/10.31991/2594-8474/v1n12017/coroa

Dickens, N., Haider, H., Lien, W., Simecek, J., \& Stahl, J. (2018). Longitudinal Analysis of CAD/CAM Restoration Incorporation Rates into Navy Dentistry. Military Medicine.

Mezzomo, E e Cols. Prótese Parcial Fixa - Manual de Procedimentos. Ed, Santos, 2004.

Pegoraro, L. F. (2004). Prótese Fixa, Artes Médicas.

Pivesso, P. B. (2018). Efeito da velocidade de polimerização na qualidade da impressão 3D DLP de uma resina odontológica experimental fotopolimerizável Dissertação apresentada ao Instituto de Química de São Carlos da Universidade São Paulo.

Polido, D. W. Moldagens digitais e manuseio de modelos digitais: o futuro da Odontologia. Dental Press J. Orthod. 15(5), https://doi.org/10.1590/S217694512010000500003

Protocolo de confecção de Provisórios em próteses parciais fixas (PPF) e próteses unitárias fixas (PUF) Tuesday, 28 September 2010 17:41 - Last Updated Tuesday, 28 September 2010

Rosenstiel, S. (2005). Prótese fixa contemporânea, (3a. ed.), Editora Santos

Silva, J. U. C. Técnica alternativa de confecção de provisórios para laminados e coroas metal-free. 2011. 15 f. (Trabalho de Conclusão de Curso - Graduação). Faculdade de Odontologia, Universidade Estadual Paulista, Araçatuba, 2011.

Simoneti, D. M. e S. Coroas dentárias temporárias em impressão 3D / Débora Meincke Simoneti; Tatiana Pereira Cenci, orientadora ; Mateus Bertolini Fernandes dos Santos, coorientador. - Pelotas, 2018. 
Research, Society and Development, v. 10, n. 14, e322101422117, 2021

(CC BY 4.0) | ISSN 2525-3409 | DOI: http://dx.doi.org/10.33448/rsd-v10i14.22117

Torres, T. S., Melo, B. C., Negrão L. M. A, Vasconcelos, G. L. L, \& Salles, M. M. Efeito de bebidas coradas na estabilidade de cor de resinas acrílicas polimerizadas por diferentes métodos. J Orof Invest. 2019;6(2): 18-27

Tylman, S.; Malone, W. F. P.; \& Koth, D.; Teoria e prática de prótese fixa de Tylman, Editora Artes Médicas (8a ed.).

Vasconcelos, B. E., Farias, R. S., Matos, J. D. M., Lima, J. F. M., Castro, D. S. M., \& Zogheib, L. V. A tecnologia 3D e suas aplicações na Odontologia moderna - uma revisão sistemática de literatura. Full Dent. Sci. 2018; 10(37): 